\title{
ENSINO DE CIÊNCIAS: CONSCIENTIZACCÃO AMBIENTAL POR MEIO DE UMA SEQUÊNCIA DIDÁTICA COM ALUNOS DO 6 ANO DO ENSINO FUNDAMENTAL
}

\author{
Márcia Elida Domingos Prudêncio ${ }^{1}$ \\ Juliana Pires da Silva ${ }^{2}$ \\ Rosabel Bertolin Daniel ${ }^{3}$
}

\section{INTRODUÇÃO}

$\mathrm{Na}$ atualidade as questões ambientais são cada vez mais urgentes e preocupantes para a sociedade, uma vez que o futuro das próximas gerações depende do uso que o homem faz dos recursos naturais disponíveis. Tal conscientização ambiental passa pela formação na escola de estudantes conhecedores de tal problemática que serão agentes atuantes fora do contexto escolar. Deste modo, a escola é um espaço privilegiado e importante onde à formação de valores, de atitudes sobre o Meio Ambiente deve ser construída com os alunos.

\begin{abstract}
A principal função do trabalho com o tema Meio Ambiente é contribuir para a formação de cidadãos conscientes, aptos a decidir e atuar na realidade socio ambiental de um modo comprometido com a vida, com o bem-estar de cada um e da sociedade, local e global. Para isso é necessário que, mais do que informações e conceitos, a escola se proponha a trabalhar com atitudes, comformação de valores, com o ensino e aprendizagem de procedimentos (BRASIL, 1998, p.1).
\end{abstract}

Bianchi e Melo (2009) enfatizam que a evolução dos problemas ambientais faz parte do escopo da Educação Ambiental e destacam a importância da consciência sobre as relações entre o ser humano e o seu meio. Ainda, os autores ressaltam que a escola é um meio estratégico para o desenvolvimento do tema, sendo papel do professor trazer esta discussão para a sala de aula instigando no aluno o desenvolvimento de habilidades e senso crítico sobre o cotidiano. Além disso, a temática ambiental é recomendada como tema transversal pelas diretrizes curriculares brasileiras e pela política nacional de educação ambiental para ser

Universidade Federal de Santa Catarina - UFSCmarcia.prudencio@ufsc.br Universidade Federal de Santa Catarina - UFSCjuliana.pires@ufsc.br Instituto Federal de Santa Catarina - IFSCrosabel.bertolin@ifsc.edu.br 
trabalhada nas escolas devendo ser incluída em diferentes disciplinas, em especial, aqui trataremos do ensino de ciências (BRASIL, 1998).

Por meio da disciplina de Ciências, trabalhou-se uma sequência didática sobre o tema lixo com estudantes do 6ํano do Ensino Fundamental de uma escola pública da rede estadual da cidade de araranguá, estado de Santa Catarina. O objetivo era alertar os estudantes dos benefícios do destino correto do lixo para a preservação da natureza e consequente saúde dos seres vivos; ainda, incentivá-los da importância desse descarte correto, bem como, levar esta experiência para o cotidiano deles.

A sequência foi desenvolvida na disciplina de ciências baseada em um contrato didático, onde o estudante é convidado a construir o seu próprio conhecimento na interação com os colegas, o estagiário e a situação proposta. As aulas analisadas faziam parte do estágio regência de uma aluna da graduação. Desse modo, a aplicação foi realizada pelo estagiário sem a aintervenção do professor titular da turma. O processo ocorreu durante cinco semanas, dez aulas, nas quais foram trabalhados os conceitos de lixo e de reciclagem. Ressalta-se que esse assunto foi integralmente trabalhado pelo graduando.

Em seguida, mostraremos mais detalhes de como procedeu a elaboração e realização dessa sequência, assim como, a relação com o referencial adotado e alcance ou não dos objetivos propostos.

\section{EDUCAÇÃO AMBIENTAL}

A Educação Ambiental se constituiu com base em propostas educativas oriundas de concepções teóricas e matrizes ideológicas distintas, sendo reconhecida como de inegávelrelevância para a construção de uma perspectiva ambientalista de sociedade.

A área ganhou notoriedade com a promulgação da Lei 9.795, de 27 de abril de 1999, a qual instituiu uma Política Nacional de Educação Ambiental e, por meio dela, ficou estabelecida a obrigatoriedade da Educação Ambiental em todos os níveis do ensino no Brasil. Tal lei merece ser mencionada como um marco relevante 
da história da Educação Ambiental no Brasil, porque é consequência de um processo de integração entre educadores, ambientalistas e governo (BRASIL, 1999).

Segundo Lima (2002), a escola é um espaço importante e adequado para o desenvolvimento de valores sendo, portanto, um local privilegiado para o estabelecimento de informações e conexões que criem condições e alternativas para motivar os alunos a terem atitudes conscientes e responsáveis em relação ao meio ambiente, bem como se sentirem integrantes do mesmo.

Ao conectar o conteúdo das ciências ao dia a dia, o educador torna a aprendizagem mais significativa. As oficinas pedagógicas realizadas durante as aulas se acontecem embasadas nas vivências dos alunos e nos fenômenos que ocorrem a sua volta, buscando analisá-las com o auxílio dos conceitos científicos adequados. É por meio de um ensino investigativo e provocativo que $\mathrm{o}$ aluno começa a pensar e a refletir sobre o processo de construção do conhecimento (FREIRE, 1987).

Para Carvalho (2006), a Educação Ambiental é conteúdo e aprendizado, é parâmetro e norma. Ultrapassa os conteúdos pedagógicos, se relaciona com o ser humano de forma que a troca passa a ser uma retroalimentação positiva mútua. Educadores ambientais são pessoas comprometidas com o que fazem. As escolas precisam mudar suas regras para se fazer educação ambiental de forma mais humana.

\section{METODOLOGIA}

Para alcançar o objetivo proposto, foi aplicada uma sequência didática desenvolvida em dez aulas na disciplina de ciências baseada em um contrato didático onde o estudante é convidado a construir o seu próprio conhecimento na interação com os colegas, o docente e a situação proposta. O assunto foi integralmente trabalhado pelo graduando, sem a intervenção do professor titular da turma.

Os sujeitos da pesquisa foram os estudantes do $6^{\circ}$ ano do Ensino Fundamental de uma escola da rede pública e o graduando em estágio docência.

Para análise da sequência, foram coletados dados do relato de experiência do estagiário e as atividades desenvolvidas, assim como, alguns 
questionamentos as respostas dos alunos sobre as atividades propostas a fim de verificar se os objetivos foram alcançados. A sequência foi desenvolvida na seguinte ordem:

Aula 1-2-3 - Breve introdução do tema pelo professor; Visualização de filme; Questionário realizado em sala.

$>$ Aula 4-5 - Apresentação de aula no formato de slides.

> Aula 6 - Aplicação de dinâmica de grupo: "Jogo das curiosidades" sobre o tema lixo, os alunos sentarão em um grande círculo. Será disponibilizada uma caixa fechada contendo algumas perguntas. No centro serão disponibilizadas algumas fichas contendo as resposta.

Aula 7- 8 - Aula prática - Cada aluno trará de casa embalagens e outros produtos que fazem parte do dia-a-dia das famílias que podem ser reciclados. Eles mostrarão o que trouxeram e guardarão na lixeira adequada. Para esta atividade, serão utilizadas as caixas coletoras próprias para reciclagem.

$>$ Aula 9 - Atividades escritas contendo seis questões, as quais serão feitas de forma individual em sala de aula.

Aula 10-11 - Confecção e apresentação para o professor e colegas de cartazes com as informações discutidas nas aulas anteriores. A turma será dividida em grupos de cinco alunos.

\section{ELABORAÇÃO DA SEQUÊNCIA DIDÁTICA}

O professor (estagiário) elaborou a sequência didática com a finalidade de alcançar os objetivos propostos referentes a conscientização ambiental. Deste modo, utilizou-se de diversas atividades práticas e teóricas a fim de que pudessem estimular o diálogo, evoluir os conceitos, criar conflitos cognitivos e gerar situações que propiciem a aprendizagem. Antes de detalharmos as aulas, mostraremos no quadro 1 a síntese da elaboração da sequência.

Quadro 1. Resumo do planejamento didático descrevendo os conteúdos, atividades e objetivos. 


\begin{tabular}{|c|c|c|c|}
\hline Aula & Conteúdos & Atividades & Objetivos \\
\hline $1-2-3$ & $\begin{array}{l}\text { Educação } \\
\text { Ambiental: } \\
\text { Desmatamento }\end{array}$ & $\begin{array}{l}\text { - Breve introdução } \\
\text { do tema; } \\
\text { - Visualização de } \\
\text { filme; } \\
\text { - Questionário } \\
\text { realizado em sala. } \\
\end{array}$ & $\begin{array}{l}\text { - Apresentação da sequência didática; - } \\
\text { Incentivar a conscientização ambiental através } \\
\text { da visualização do filme O Lorax: Em Busca } \\
\text { da Trúfula Perdida; - Conhecer as concepções } \\
\text { prévias dos alunos sobre Educação } \\
\text { Ambiental. }\end{array}$ \\
\hline 4- 5 & $\begin{array}{l}\text { Educação } \\
\text { Ambiental: lixo, } \\
\text { reciclagem } \\
\text { sustentabilidade. }\end{array}$ & $\begin{array}{l}\text {-Apresentação de } \\
\text { aula no formato de } \\
\text { slides }\end{array}$ & $\begin{array}{l}\text { - Compreender o que é lixo; reconhecer os } \\
\text { benefícios do destino certo do lixo para a } \\
\text { preservação da natureza e para a saúde dos } \\
\text { seres humanos; compreender e entender o } \\
\text { destino do lixo; incentivar a coleta seletiva; } \\
\text { explicar os conceitos de reduzir, reutilizar e } \\
\text { reciclar. }\end{array}$ \\
\hline 6 & $\begin{array}{l}\text { Educação } \\
\text { Ambiental: } \\
\text { reciclagem, } \\
\text { reutilização e } \\
\text { redução do lixo. }\end{array}$ & $\begin{array}{l}\text { - Aplicação de } \\
\text { dinâmica de grupo: } \\
\text { "Jogo das } \\
\text { curiosidades", } \\
\text { sobre o tema lixo. }\end{array}$ & $\begin{array}{l}\text { - Esclarecer as dúvidas e sensibilizar os } \\
\text { alunos sobre a responsabilidade de cada um } \\
\text { nos cuidados referentes à redução, } \\
\text { reutilização e reciclagem do lixo. }\end{array}$ \\
\hline 7-8 & $\begin{array}{l}\text { Educação } \\
\text { Ambiental: } \\
\text { Reciclagem, } \\
\text { coleta seletiva. }\end{array}$ & $\begin{array}{l}\text { - Aula prática - } \\
\text { Cada aluno trará de } \\
\text { casa embalagens } \\
\text { e aprenderá a fazer } \\
\text { a coleta seletiva } \\
\text { nas caixas da } \\
\text { escola. }\end{array}$ & $\begin{array}{l}\text { - Propor pesquisa sobre materiais recicláveis; } \\
\text { - Conhecer a prática de reciclagem na escola } \\
\text { identificando os tipos de lixo; } \\
\text { - Conscientizar da importância da coleta } \\
\text { seletiva do lixo para o reaproveitamento dos } \\
\text { resíduos. }\end{array}$ \\
\hline $9-10-11$ & $\begin{array}{l}\text { Educação } \\
\text { Ambiental: } \\
\text { Desmatamento, } \\
\text { lixo, reciclagem, } \\
\text { reutilização e } \\
\text { redução do lixo } \\
\text { e coleta seletiva. }\end{array}$ & $\begin{array}{l}\text { - Atividades escrita } \\
\text { contendo seis } \\
\text { questões. } \\
\text { - Confecção de } \\
\text { cartazes em } \\
\text { grupo,apresentação } \\
\text { à turma e } \\
\text { exposição nos } \\
\text { murais do colégio. }\end{array}$ & $\begin{array}{l}\text {-Reconhecer a aprendizagem dos alunos } \\
\text { sobre a conscientização ambiental: sobre o } \\
\text { destino e reaproveitamento do lixo; } \\
\text { - Avaliar a aprendizagem dos alunos sobre o } \\
\text { conteúdo. }\end{array}$ \\
\hline
\end{tabular}

Fonte: próprios autores.

\section{RESULTADOS E DISCUSSÃo}

No início da aula, o professor explicou os objetivos propostos com a atividade e introduziu o tema a ser discutido. Após, assistiram um filme para contextualizar a problemática. Os estudantes se mostraram interessados na atividade.

$\mathrm{Na}$ discussão de questões relacionadas ao filme e ligadas com o tema sustentabilidade, como por exemplo: Qual o principal motivo do desmatamento? A maioria dos alunos respondeu "para ganhar dinheiro". O resultado desta primeira atividade foi muito proveitosa, sendo que os alunos participaram ativamente da aula relacionando os conceitos ao seu cotidiano. Esta atividade teve o intuito, de forma 
divertida,de introduzir o tema a ser tratado em toda a sequência, buscando incentivar a conscientização ambiental e conhecer as concepções prévias dos alunos sobre Educação Ambiental.

Na aula teórica, questões como, o que é lixo, explicando a redução, bem como, a destinação, reutilização e reciclagem foram trabalhadas. No momento da apresentação, os alunos mostraram interesse ao tema, bem como, fizeram questionamentos relacionados com o cotidiano deles. Nesta parte expositiva da aula, a qual se discutia sobre os lixões, os alunos manifestaram interesse de visitar o lixão do município, uma vez que, não tinham conhecimento da existência do mesmo. Da mesma forma, mencionaram as entidades que fazem a separação do lixo e, também, as que fazem a incineração. Isso se tornou para eles algo de extrema relevância, talvez, pelo fato de nunca ouvirem falar sobre o assunto e porque aprenderiam mais com o contato direto do referido assunto em sua execução.

$\mathrm{Na}$ atividade escrita alguns alunos demonstraram mais dificuldade para realizar a atividade pedindo auxílio ao professor, mas, conseguiram compreender o que é o lixo e saber dos benefícios e malefícios do destino do lixo. Assim como, incentivá-los a coleta seletiva explicando os conceitos de reduzir, reutilizar e reciclar. E mais ainda desenvolver no aluno o senso crítico na preservação do meio ambiente.

O "Jogo das curiosidades", em que se trabalhou numa dinâmica de grupo, a maioria dos alunos acertava as respostas, mas teve alguns que erraram. Então, o professor procurou esclarecer as dúvidas e sensibilizar os alunos sobre a responsabilidade de cada um nos cuidados referente ao correto descarte do lixo, assim como, à redução, reutilização e reciclagem do lixo. Os alunos adoraram essa dinâmica. Observou-se grande empenho e desenvolvimento dos alunos referente ao conteúdo aplicado até aquele momento, como também, pelo espírito de competição que os levaram a se integrarem mais com a turma, fazendo com que cada um prestasse atenção em todas as perguntas e respostas, adquirindo conhecimento.

Na separação do lixo, cada aluno trouxe de casa alguns tipos de lixos para serem separados e descartados corretamente nas lixeiras da escola. $O$ intuito foi ensinar aos alunos a correta separação de destinação da diversidade dos tipos de lixos para que eles repliquem isso para o cotidiano deles. Cada aluno mostrou o que trouxe e guardou na lixeira adequada. Para esta atividade, foram utilizadas as caixas coletoras próprias para reciclagem pertencentes à escola. Após a separação 
do lixo, foram discutidas questões sobre sustentabilidade e a destinação do lixo. A aula foi muito produtiva, onde cada aluno participou com a atividade da separação do lixo e também na discussão sobre as questões levantadas sobre o tema. Muitas vezes, com a correria do dia a dia, passa-se despercebida a importância da separação do lixo. Destavez, aplicou-se uma lista de exercícios para ser entregue no final da aula. Os alunos fizeram alguns questionamentos sobre dúvidas, mas todos responderam e entregaram ao final da aula. Esta atividade foi corrigida e atribuída um conceito ao aluno.

O método realizado possibilitou ao aluno conhecer a prática de reciclagem na escola identificando os tipos de lixo, e, saber que aquele lixo que iria para o lixão irápara a coleta seletiva para o reaproveitamento dos resíduos. Deste modo, observa-se a importância de conscientizar nossos alunos.

$\mathrm{Na}$ última atividade com os alunos, o professor encerrou o tema proposto com a confecção de cartazes referentes àsinformações discutidas nas aulas anteriores. Após, cada grupo apresentou os cartazes ao professor e aos colegas. No final, os mesmos foram expostos nos murais do colégio. Após a apresentação dos cartazes, foi distribuído e discutido com os alunos a Cartilha do Meio Ambiente. Todos os alunos participaram ativamente construindo seus cartazes e fazendo vários questionamentos ao professor. Mostraram interesse na aula eresultado ao que Ihes foi proposto. Nesta aula, pôde-se perceber que os alunos gostam de atividades diversificadas, no entanto, exige mais trabalho do professor, mas o resultado é mais significativo tanto para os alunos quanto para o professor. Os cartazes seriam expostos na feira de ciências que seria realizada um mês após o término da sequência.

Neste momento o aluno já reconheceu a aprendizagem sobre a conscientização ambiental,sobre o destino e reaproveitamento do lixo, pois já usa o que aprendeu na realização de uma atividade com a problemática relatada no trabalho. Por fim, pode-se avaliar a aprendizagem dos alunos sobre o referido conteúdo.

\section{CONSIDERAÇÕES FINAIS}


Percebe-se uma evolução dos alunos na conscientização ambiental de maneira que os mesmos foram adquirindo autonomia na realização das atividades tornando evidente a importância de refletir sobre a Educação Ambiental discutindo temas como sustentabilidade, lixo e reciclagem. Desse modo, pode-se presumir que a postura didática adotada pelo professor surtiu efeitos que poderão levar os alunos a exercer em seus cotidianos uma consciência ambiental.

Na construção dos cartazes e apresentação dos grupos em sala para a turma, e também, na exposição realizada na feira de ciências, os alunos demonstraram autonomia, apresentaram os cartazes ao público presente não sendo necessária a presença direta do professor.

\section{REFERÊNCIAS}

BIANCHI, Cristina dos Santos; MELO,Waisenhowerk Vieira de. Desenvolvimento de um projeto de ação pedagógica para conscientização ambiental com alunos de 9응 ano do Ensino Fundamental. Revista Electrónica de Enseñanza de LasCiencias, v. 8, n. 3, p.976-1003,2009. Disponível em: <http://reec.uvigo.es/volumenes/volumen8/ART12_Vol8_N3.pdf>. Acesso em: 30 nov. 2015.

BRASIL. Ministério do Meio Ambiente. Lei n. 9.795/1999. Dispõe sobre a educação ambiental, institui a Política Nacional de Educação Ambiental e dá outras providências. Disponível em: Acesso em: 22 abr. 2010.

BRASIL. Ministério da Educação e do Desporto. Parâmetros Curriculares Nacionaishttp://portal.mec.gov.br/seb/arquivos/pdf/meioambiente.pdf.Disponível em: Acesso em: 17mar. 2016.

CARVALHO, I. C. M. Educação ambiental: a formação do sujeito ecológico. 2.ed. São Paulo: Cortez, 2006.

FREIRE, P. Pedagogia do oprimido. 17 ed. Rio de Janeiro:Paz e Terra. 1987.

LIMA, G. F. C. Crise ambiental, educação e cidadania. In: LOUREIRO, C.F.B.; LAYRARGUES, P.P. \& CASTRO, R.S. (Orgs.). Educação ambiental: repensando o espaço da cidadania. São Paulo: Cortez, 2002. 